\title{
Relationship between PAH biotransformation as measured by biliary metabolites and EROD activity, and genotoxicity in juveniles of sole (Solea solea)
}

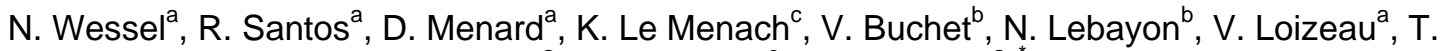 \\ Burgeot $^{a}, \mathrm{H}$. Budzinski ${ }^{\mathrm{c}}$ and F. Akcha ${ }^{\mathrm{a},{ }^{*}}$
}

\author{
${ }^{a}$ Ifremer, Department of Biogeochemistry and Ecotoxicology, Rue de l'lle d'Yeu, BP 21105, 44311 \\ Nantes 03, France \\ ${ }^{\mathrm{b}}$ Ifremer, Laboratory of Adaptation, Reproduction and Nutrition of Marine Fish, 29280 Plouzané, \\ France \\ ${ }^{\mathrm{c}}$ ISM, LPTC, University of Bordeaux 1, 351 Cours de la Libération, 33405 Talence, France \\ * Corresponding author: F. Akcha, Tel.: +33 2403742 08; fax: +33 2403742 41, email address : \\ fakcha@ifremer.fr
}

\begin{abstract}
:
Polycylic aromatic hydrocarbons (PAHs) are ubiquitous contaminants in the marine environment. Their toxicity is mainly linked to the ability of marine species to biotransform them into reactive metabolites. PAHs are thus often detected at trace levels in animal tissues. For biomonitoring purposes, this findings have two main consequences, (i) the determination of the PAH tissue concentration is not suitable for the evaluation of individual exposure to PAHs (ii) it can explain sometimes the lack of correlations obtained with relevant markers of toxicity such as genotoxicity biomarkers.
\end{abstract}

The aim of the present study was to better investigate the link between PAH exposure and genotoxicity in marine flatfish. During a laboratory experiment, juvenile soles were exposed for four weeks to a mixture of three PAHs, namely benzo[a]pyrene, fluoranthene and pyrene, followed by one week of depuration. Fish were exposed via the trophic route to a daily PAH concentration of $120 \mu \mathrm{g} / \mathrm{g}$ food. Fish were sampled at different time points. The bioavailability and the biotransformation of PAHs were assessed by the measurement of biliary metabolites using a sensitive UPLC MS/MS method. The 7-ethoxyresorufine-O-deethylase was also measured in liver subcellular fractions as a biomarker of phase I biotransformation activities. Genotoxicity was assessed in parallel by the measurement of DNA strand breaks in fish erythrocytes by the alkaline comet assay.

During this study, the high amount of PAH metabolites produced in sole demonstrated the bioavailability of PAHs and their biotransformation by fish enzymes. A positive correlation was observed between the level of hydroxylated PAH metabolites and genotoxicity as measured by the alkaline comet assay.

Keywords: Ecotoxicology; Sole; PAH; Metabolites; EROD; Comet assay 
In ecotoxicology, there is a need to better assess the exposure level of organisms to chemical pollutants to investigate their toxic effects and their potential impact in the environment. Polycyclic aromatic hydrocarbons (PAHs) present most of the properties required to be classified as Persistent Organic Pollutants (POPs), except the ability to bioaccumulate in organisms (Nfon et al., 2008). As a matter of fact, PAH bioaccumulation is only observed in the first trophic levels. At higher levels, organisms have the ability to biotransform and to eliminate them. As a consequence, PAHs are only detected at trace levels in the tissues, that is the case in fish. In order to assess the level of PAH exposure, several analytical protocols were developed these last years to detect and quantify several PAH metabolites in biological fluids such as plasma and bile (Zhu et al., 2008).

In the present study, the link between PAH exposure as measured by biliary metabolites and genotoxicity was investigated in a flatfish specie, Solea solea. The EROD activity was also measured as an indicator of the activity of cytochrome P450-1A1 enzyme that is known to be implicated in the biotransformation of PAHs.

Soles were exposed in vivo to an equimolar mixture of Benzo[a]pyrene (BaP), Pyrene (Pyr), and Fluoranthene (Fluo) via the trophic way to a final concentration of $120 \mu \mathrm{g}$ PAHs/g of food. Fish were fed ad-libitum with Dana-ex 1562 (Dana Feed AS). The estimated feeding rate was around $0.8 \%$ of body weight per day. In parallel, a control group was fed with food prepared with the solvent used to dissolve the PAHs (Isooctane/Toluene, 90/10). Exposure was conducted for four weeks, followed by one week of depuration. Samplings occurred at days $0,2,7,14$ and 28 of exposure and at the end of the 7 day-depuration period. At each sampling point, 7 to 10 fish were sampled in both assay groups for chemical and biological analysis.

For each sampled fish, biometric parameters (fish and liver weight) were measured in order to determinate the hepato-somatic ratio (HSR), which is commonly used as a growth indicator. The gall bladder was sampled individually for the measurement of biliary hydroxylated PAH metabolites (3-OH BaP, 9-OH BaP, 3-OH Fluo, 1-OH Pyr) using a novel and sensitive method based on Ultra Pressure Liquid Chromatography coupled to tandem Mass Spectrometry (UPLC/MS/MS) (Le Dû-Lacoste et al., submitted). The liver of each individual was sampled in order to determine the Ethoxyresorufine-O-Deethylase activity (EROD) as an indicator of phase I biotransformation activities. EROD activity was measured in the S9 subcellular liver fraction according to the method of Burke and Mayer (1974) adapted for microplate reader. For genotoxicity assessment, the alkaline comet assay was applied in fish erythrocytes as previously described by Akcha et al. (2003). The blood from each sampled individual was withdrawn in a freezing medium and stored in liquid nitrogen. $A$ trypan blue viability test was performed on each defrosted blood sample prior to the comet assay. For each sample, two slides were prepared. For each slide, the DNA of 75 nuclei was analysed by the measurement of the percentage of DNA present in the comet tail and the Olive tail moment (OTM) (Kinetic Imaging 4.0).

During the experiment, no difference in HSR value was observed between the control (11.87 $\left.10^{-3} \pm 3.4310^{-4}\right)$ and the PAH-exposed groups (11.55 $\left.10^{-3} \pm 3.4610^{-4}\right)$. Considering the relative short time of the experiment, a negative effect on fish growth was not expected.

Concerning the level of hydroxylated PAH metabolites (Figure 1A), data were mathematically transformed $(\operatorname{Ln} \mathrm{x})$ for normalization. Only trace levels were detected in the control group, while a significant time-dependent increase was observed in the $\mathrm{PAH}$-exposed group (Main effect ANOVA, $p<0.01)$. These results demonstrated the bioavailability of PAHs for sole and their biotransformation by fish enzymes.

At the end of the exposure period, the level of $\mathrm{PAH}$ metabolites in the exposed group reached more than $74 \mu \mathrm{g}$ of metabolites per $\mathrm{g}$ of bile. During all the experiment, the $1-\mathrm{OH}-$ Pyr, commonly used as a marker of PAH exposure, was the major metabolite produced, followed by the $3-\mathrm{OH}-\mathrm{Fluo}$ and the $3-\mathrm{OH}-\mathrm{BaP}$, while only trace levels of $9-\mathrm{OH} \mathrm{BaP}$ were quantified. Following only one week of depuration, more than $99 \%$ of the detected metabolites were excreted, demonstrating that sole rapidly eliminate PAHs. 
Despite the production of high amount of PAH metabolites, no difference in EROD activity was observed between control and PAH-exposed fish (Figure 1B) (Main effect ANOVA, $p=$ 0.90). Moreover, no time-variation in EROD activity was observed whatever the experimental group (Main effect ANOVA, $p=0.32$ ). The lack of a PAH effect on EROD activity could be explained by the antagonist effect of the different PAHs used for the exposure. In fact, BaP is considered as an inductor of the EROD activity, while an inhibitory effect on this activity was already demonstrated in fish for Fluo and Pyr (Willett et al., 2001 ; Kopecka-Pilardczyk and Correia, 2009).

Comet data were analysed by a main effect ANOVA (Statistica 8.0 Soft). The results of this analysis showed a significant effect of PAH exposure on the level of DNA strand breaks in fish erythrocytes $(p=0.001)$. This genotoxic effect is responsible for an increase respectively of $30 \%$ and $17 \%$ in OTM and Tail DNA values (Figure 2). Whatever the experimental group (control, PAH-exposed), no time-effect on comet parameters was demonstrated ( $p=0.90$ ). That may be due to the relatively high level of DNA damage measured at the beginning of the experiment. The genotoxic effect measured is thought to result from the absorption and the biotransformation of PAHs in sole, as previously demonstrated by the analysis of biliary PAH metabolites. Among the three selected PAHs, BaP and Fluo have already been shown to be genotoxic in fish (Woo et al., 2006). In the present study, the DNA strand breaks induced by PAH exposure are though to result from both the induction of an oxidative stress by pro-oxidant PAH metabolites and by the enzymes involved in the repair of both oxidative DNA damage and adducts.

All the parameters measured during this study were matched in order to check for correlations (Table 1). The level of biliary hydroxylated PAH metabolites was found to be positively correlated with the level of DNA strand breaks $(N=60, p<0.05, R=0.312$ and 0.291 with Tail DNA and OTM respectively). This correlation is in accordance with the expected role of PAH biotransformation in the induced genotoxicity. A negative correlation was found between the HSR and the level of DNA strand breaks, that could illustrate the possible consequences at physiological level of toxic events occurring at molecular level $(\mathrm{N}=61, \mathrm{p}<0.05, \mathrm{R}=-0.260)$. No correlation was observed between EROD and the other measured parameters.

During the present study, the exposure of sole via the trophic way lead to a significant production of $\mathrm{PAH}$ metabolites in sole as demonstrated by the increase in the level of hydroxylated PAH metabolites in the bile. Despite an evident biotransformation of PAHs in sole, no effect was observed on EROD activity. This latter result could be explained by the antagonist effect on this activity of the individual compounds constituting the PAH mixture. A positive correlation between $\mathrm{PAH}$ exposure as measured by biliary metabolites and the genotoxic effect was demonstrated, validating the use of metabolite detection as a suitable marker of PAH exposure in fish.

\section{Acknowledgements}

This project was supported by the Agence Nationale pour la Recherche (ANR, ANR-06PVULN-013) and Ifremer (French Institute for Exploitation of the Sea).

\section{References}

Akcha, F., Vincent-Hubert, F., Pfohl-Leszkowicz, A. (2003). Mutat. Res., 534, 21-32.

Burke, D., and Mayer, R. T. (1974). Drug Metab. Dispos., 2: 583-588.

Kopecka-Pilardczyk, J., and Correia, A. D. (2009). Ecotoxicol. Environm. Safety, 72: 12961302.

Le Dû-Lacoste, M., Wessel, N., Le Menach, K., Pardon, P., Akcha, F., Budzinski, H., submitted to J. Chrom. B. 
Nfon, E., ,Cousins, I. T., Broman, D. (2008). Sci. Total Environ., 397, 190-204.

Willett, K.L., Wassenberg, D., Lienesch, L., Reichert, W., Di Giulio, R.T. (2001). Toxicol. Appl. pharmacol., 177, 264- 271.

Woo, S., Kim, S., Yum, S., Yim, U., Lee T. (2006). Mar. Poll. Bull. 52, 1768-1775.

Zhu, S., Li, L., Thornton, C., Carvalho, P., Avery, B. A., Willett, K. (2008). J. Chrom., 863B, 141-149.

\section{Figures}
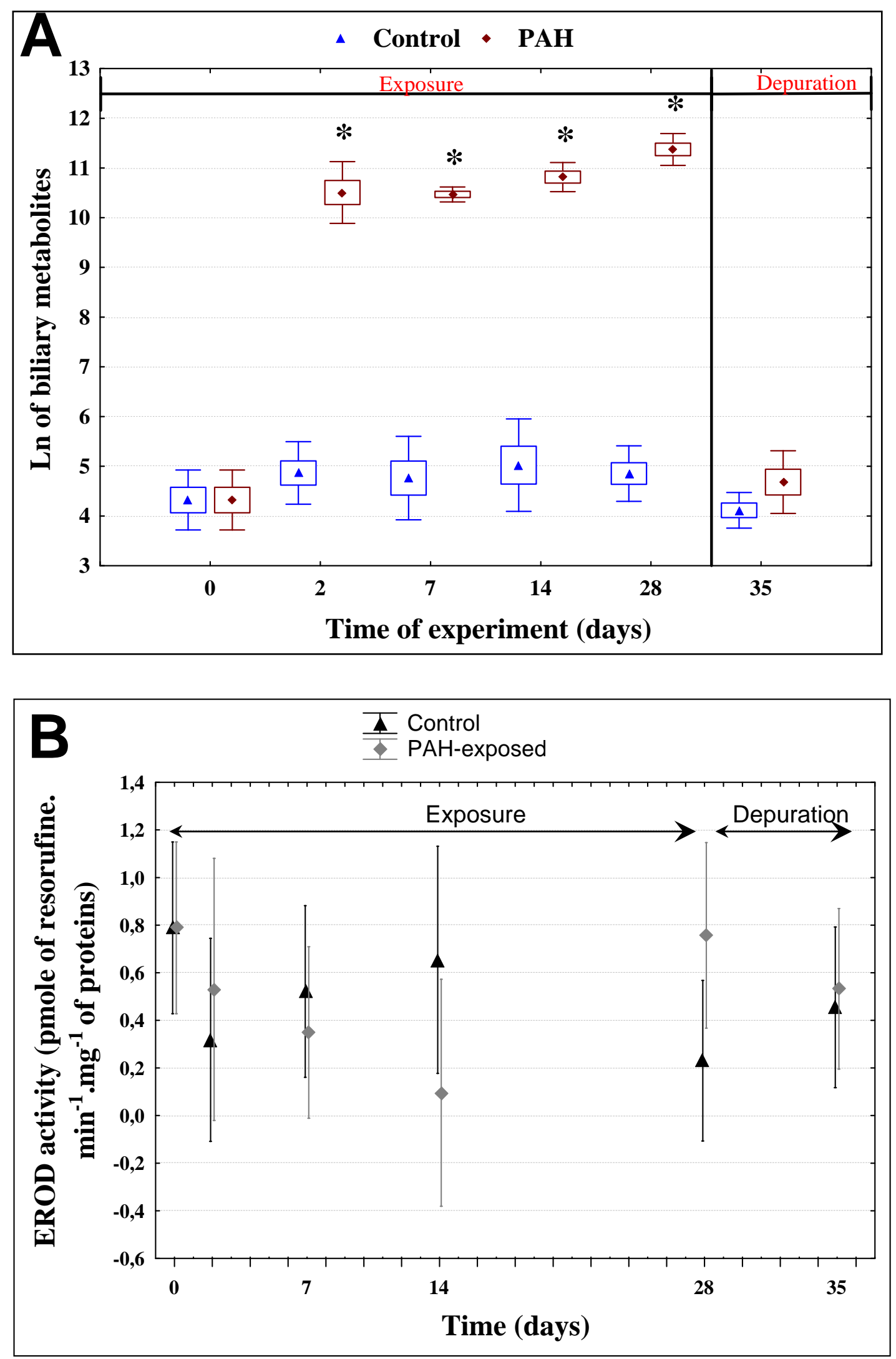
Figure 1: Levels of biliary hydroxylated metabolites (A) and EROD activity (B) in juveniles of sole from both control and $\mathrm{PAH}$-exposed group. Boxes denote standard error and whiskers denote 0.95 confidence interval, *: significant differences between groups (Tukey, $p<0.01$ ).

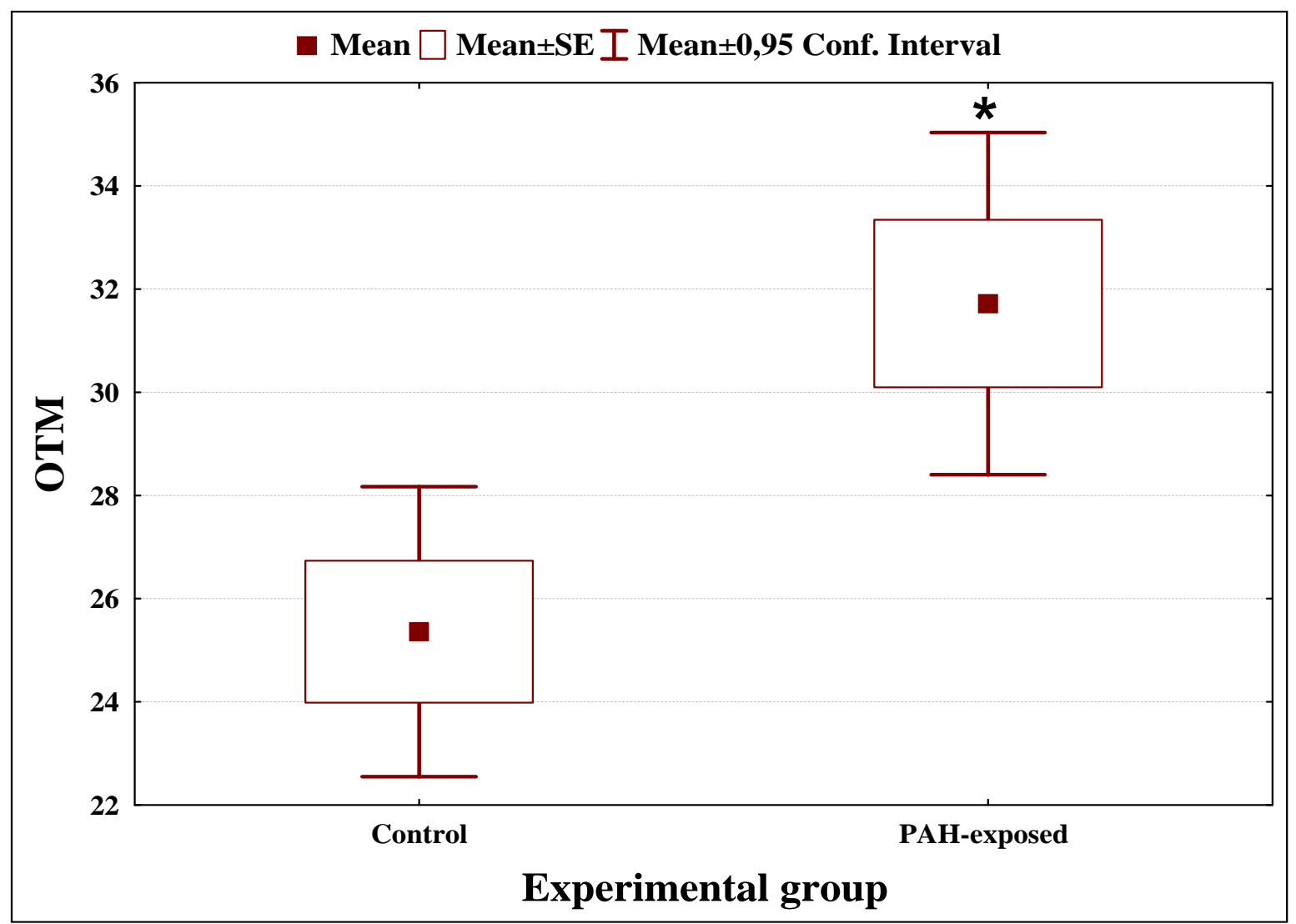

Figure 2: Levels of DNA strand break in juveniles of sole from both control and $\mathrm{PAH}$-exposed groups. Boxes denote standard error and whiskers denote 0.95 confidence interval, *: significant differences between groups $(p<0.01)$. 
Table 1: Correlation matrix among the chemical and biological parameters measured in sole

\begin{tabular}{|c|c|c|c|c|c|}
\hline HSR & $\begin{array}{c}R(X, Y) \\
p\end{array}$ & HSR & & & \\
\hline Tail DNA & $\begin{array}{c}R(X, Y) \\
p\end{array}$ & $\begin{array}{l}-0,260 \\
0,043\end{array}$ & Tail DNA & & \\
\hline Отм & $\begin{array}{c}R(X, Y) \\
p\end{array}$ & $\begin{array}{l}-0,224 \\
0,082\end{array}$ & $\begin{array}{l}0,936 \\
0,000\end{array}$ & Отм & \\
\hline $\begin{array}{l}\text { Ln (OH-PAH } \\
\text { metabolites) }\end{array}$ & $\begin{array}{c}R(X, Y) \\
p\end{array}$ & $\begin{array}{l}-0,087 \\
0,482\end{array}$ & $\begin{array}{l}0,312 \\
0,015\end{array}$ & $\begin{array}{l}0,291 \\
0,024\end{array}$ & $\begin{array}{l}\text { Ln (OH-PAH } \\
\text { metabolites) }\end{array}$ \\
\hline EROD & $\begin{array}{c}R(X, Y) \\
p\end{array}$ & $\begin{array}{c}-0,238 \\
0,100 \\
\end{array}$ & $\begin{array}{l}-0,001 \\
0,996\end{array}$ & $\begin{array}{l}0,030 \\
0,849 \\
\end{array}$ & $\begin{array}{c}-0,119 \\
0,436 \\
\end{array}$ \\
\hline
\end{tabular}

